\title{
El policial en los policiales. Retóricas de ficción en un noticiero de casos criminales (Cámara del crimen)
}

\author{
Crime Fiction in Crime News. Fiction Rhetorics in a Television Crime News Show \\ (Cámara del crimen)
}

\section{HERNÁN MALTZ}

CONICET / UniversidAD de Buenos Aires (ARGENTINA) hermaltz@gmail.com

Doctorando en el área de Literatura y Licenciado en Sociología, ambos por la Universidad de Buenos Aires. Becario doctoral del Consejo Nacional de Investigaciones Científicas y Técnicas, con lugar de trabajo en el Instituto de Filología y Literaturas Hispánicas “Dr. Amado Alonso" (Universidad de Buenos Aires). Integra proyectos de investigación sobre historia e historiografía de la literatura policial en la Argentina.

RECIBIDO: 23 de julio de 2015

ACEPTADO: 7 de diciembre de 2015

ReSumen: Proponemos analizar las estrategias narrativas empleadas para contar casos criminales en el programa Cámara del crimen, conducido por Ricardo Canaletti en la señal televisiva $T N$ (Todo Noticias), durante las emisiones de 2014. Sostenemos la tesis de que para contar casos reales hay una necesaria apoyatura en discursos ficcionales (fílmicos y literarios), especialmente del género policial. Nos servimos de elementos teóricos de la semiótica, fundamentalmente en lo que respecta a una teoría de los géneros que contemple los aspectos enunciativos, temáticos y retóricos de todo discurso. También apelamos a motivos, recursos y estilos específicos del cine y la literatura policiales, fuentes indispensables para pensar la transposición selectiva de ciertas retóricas empleadas en Cámara del crimen.

PALABRas Clave: Policiales, policial, retórica, género, ficción.
ABSTRACT: I propose to analyze the narrative strategies employed to tell criminal cases in Cámara del crimen, a program led by Ricardo Canaletti in the television signal TN (Todo Noticias), during its emissions in 2014. I hold that for narrating real cases, it is necessary to have a support in fictional discourses (literature and films), specially related to the detective fiction. I use theoretical elements of semiotics, mainly in regard to a theory of genres that includes the enunciative, thematic and rhetorical aspects of all discourse. I also employ motives, ways and specific styles of detective fiction's films and literature, indispensable sources to analyze the selective transposition of certain rhetorical aspects in Cámara del crimen.

KEY WORDS: Crime news, crime fiction, rhetoric, genre, fiction.

Maltz, Hernán. “El policial en los policiales. Retóricas de ficción en un noticiero de casos criminales (Cámara del crimen)". Kamchatka. Revista de análisis cultural 7 (Junio 2016): 321-339

DOI: 10.7203/KAM.7.6732 ISSN: 2340-1869 


\section{Introducción ${ }^{1}$}

En un contexto de auge de la literatura policial a nivel nacional e internacional, que se nutre cada año de novedades editoriales, reimpresiones, reediciones de libros clásicos, colecciones enteras dedicadas al género, festivales, jornadas, concursos, premios, creaciones y transposiciones cinematográficas, etcétera, observamos que el éxito del policial traspasa la especificidad del campo literario-cinematográfico ${ }^{2}$. Como ya ha señalado oportunamente Link (2003), el policial funciona como un dispositivo que permite reflexionar en torno a las condiciones que estructuran todo discurso. En esa dirección, el objetivo de este trabajo consiste en analizar un fenómeno transpositivo particular: la aprehensión de ciertas retóricas del género policial por parte de un noticiero de casos criminales, Cámara del crimen, inaugurado en marzo de 2014 y conducido por Ricardo Canaletti en la señal televisiva Todo Noticias $(T N)^{3}$.

Consideramos que Cámara del crimen debe ser enmarcado en un corpus de ficciones argentinas, más que de noticieros. Una lista de los programas de los últimos años que se aproximan de distintas formas al policial y que constituyeron apuestas fuertes -especialmente en el panorama de una televisión de aire que tiende a ponderar la producción de tiras diarias costumbristas- debe incluir a: Tumberos (2002), Los simuladores (2002-2003), Mosca y Smith (2004-2005), Hermanos y detectives (2006), Malicia (2015), Cromo (2015) y Variaciones Walsh (2015). Sin embargo, el policial y el costumbrismo no son, desde luego, excluyentes entre sí; ambos conviven en distintas tiras diarias de la productora Pol$k a$, en las que incluso la historia de amor ocupa un lugar importante -por no decir primordial-, como Poliladron (1995-1997), 22, el loco (2001), 099 Central (2002), Sin código (2004-2006) o Noche y día (2014-2015). Frente a ellas, vale traer a cuenta la tira semanal Mujeres asesinas (2005-2008), que

\footnotetext{
${ }^{1}$ Agradezco los pertinentes comentarios de Leticia Moneta, Marita Soto y Oscar Steimberg, que me permitieron refinar el análisis del presente artículo, además de las evaluaciones anónimas que dieron lugar a pertinentes modificaciones en la introducción del texto.

${ }^{2}$ La ficción policial como "clave hermenéutica" (Grieco y Bavio, 2016), como grilla que hace inteligible lo social, se impone como paradigma en muchos análisis. Por ejemplo, ante el escándalo público que significó -y significa- la muerte del fiscal Alberto Nisman el 18 de enero de 2015, encontramos una nota del reconocido antropólogo Alejandro Grimson, que comienza con una introducción basada en el relato policial y en la asunción de una subjetividad detectivesca por parte de los argentinos (Grimson, 2015).

${ }^{3}$ Desde sus comienzos, el programa se emite los sábados a la tarde y hay una repetición los domingos. Originalmente duraba una hora y media y, desde fines de 2014, se extendió a dos horas. Las emisiones están disponibles en la web de $T N$, en el siguiente enlace: ‘http://tn.com.ar/programas/camara-del-crimen’. Durante 2015 el programa consolidó su formato, pero en este trabajo tomamos como corpus las emisiones de 2014, en cuyo conjunto podemos apreciar un itinerario hacia el establecimiento de sus formas y estilos característicos. En cuanto a Ricardo Canaletti, se trata del jefe de la sección de policiales del diario Clarín. Desde 2014 conduce el mencionado ciclo televisivo. Además publicó, en 2014 y 2016, dos volúmenes de Crímenes sorprendentes de la historia argentina.
} 
también fue producida por Pol-ka pero que en todo caso presenta una mayor afinidad con las otras series mencionadas. En otro tipo de formato, Juan Sasturain condujo, a través del canal Encuentro, el ciclo de divulgación cultural Disparos en la biblioteca (2014-2015), con interesantes episodios que abordan el género policial temática y retóricamente. En cada capítulo se narra un aspecto del desarrollo del género en la Argentina (una obra, un autor, una problemática, etcétera), a través del empleo de formas de componer propias del policial, particularmente con elementos tomados del cine noir norteamericano. Cada emisión consiste en un "caso" y Sasturain es presentado como un "detective literario", con los rasgos del private eye de la serie cinematográfica ${ }^{4}$. En la misma y particular línea podemos ubicar al programa periodístico Cámara del crimen, que, si bien se basa en contar casos policiales reales, también se configura, al igual que el programa de Sasturain, con un fuerte componente retórico tomado explícitamente de la literatura y el cine policiales. Sin acabar en este párrafo con la lista de las presencias del amplio género policial en la televisión argentina, al menos merece una mención el ciclo Policías en acción, una suerte de adaptación del formato norteamericano del reality sobre las actividades de los policías, y que comparte con Cámara del crimen el uso de retóricas tomadas indudablemente del ámbito de la ficción (aunque Policías en acción se sirve fundamentalmente de aspectos tomados de otro género: la historieta).

Para abordar el objetivo propuesto -el análisis de formas específicas de composición discursiva en Cámara del crimen-, nos servimos de elementos teóricos de la semiótica, fundamentalmente en lo que respecta a una teoría de los géneros que contemple los aspectos temáticos, retóricos y enunciativos de todo discurso (Steimberg, 2013a) ${ }^{5}$. Si estos tres factores se tornan indisociables en el funcionamiento de todo dispositivo, en este caso nos interesa centrarnos en el componente retórico, que "no es un adorno del discurso, sino una dimensión esencial a todo acto de significación” (Bremond, 1975: 9). En este sentido, proponemos detenernos en la manera en que Cámara del crimen emplea formas de componer retóricas- propias del género policial (aunque esto no signifique, por supuesto, que los métodos compositivos del programa televisivo se remitan únicamente al policial). Para abordar este pasaje, por lo tanto, también apelamos a motivos, recursos y estilos específicos del cine y la literatura policiales,

\footnotetext{
${ }^{4}$ Si bien aquí, como se ve, recapitulamos producciones para la televisión de aire, a la mención de los programas de divulgación cultural de Sasturain debemos sumar el aporte de Silvia Hopenhayn, cuya labor en la misma dirección resulta completamente elogiable, a través de distintos programas emitidos desde hace varios años por la señal de cable Canal (á), entre los que podemos destacar dos que son especialmente pertinentes para nuestro corpus: Policiales de colección y Libros que matan.

${ }^{5}$ Esta metodología dista de ser novedosa: recordemos que el estudio de Fiske y Hartley, Reading Television, publicado originalmente en 1978, ya había utilizado la semiótica en los estudios sobre televisión, particularmente en los capítulos "The signs of television" y "The codes of television" (Fiske y Hartley, 2003). Otro estudio que se sirve de la semiótica es Televisuality: Style, Crisis, and Authority in American Television, particularmente en el capítulo "Franchiser: Digital Packaging / Industrial-Strength Semiotics" (Caldwell, 1995).
} 
fuentes indispensables para pensar la transposición selectiva de ciertas retóricas empleadas en Cámara del crimen $^{6}$.

En el desarrollo de nuestra exposición distinguimos cinco dimensiones en las que identificamos dichas retóricas: la presentación del programa; el modo de presentarse del conductor y del co-conductor; la ambientación espacial del propio programa; el modo de presentar y representar los casos referidos; y, finalmente, los usos de la escenificación en la narración de las historias. El último ítem de la lista es, en verdad, otro modo particular de representar los casos referidos; sin embargo, dada su especial relevancia -incluso como marca distintiva del programa-, optamos por desarrollarla en un apartado distinto.

Trabajamos con una hipótesis de fondo, no como un fin a corroborar o refutar, sino como una guía para orientar las observaciones, descripciones y análisis. Sostenemos que, para contar casos reales, en Cámara del crimen hay una necesaria apoyatura en discursos ficcionales, literarios y fílmicos, especialmente del género policial.

\section{Desarrollo}

\subsection{Presentación del programa}

El propio sintagma que da título al programa, "Cámara del crimen”, se presta a una ambigüedad interpretativa: en principio, el carácter televisivo de la emisión nos induce a figurarnos una idea del dispositivo técnico que registra imágenes animadas para el cine o la televisión. Sin embargo, en la propia presentación del programa encontramos la representación de una suerte de espacio lóbrego: una imagen de un sitio con ladrillos oscuros sin revocar, dentro del que figuran palabras escritas en letras rojas, mayúsculas y dispuestas de manera vertical: "CONDENA", "ASESINATO", "EXPEDIENTE", "ESCENA DEL CRIMEN", "SOSPECHOSO", "ADN" -y al lado de esta palabra vemos una huella digital, también en rojo-. La imagen se focaliza sucesivamente en cada uno de estos vocablos, significantes propios de la crónica policial pero también de la ficción. Luego de esta secuencia, el enfoque retrocede y se aleja de ese espacio lóbrego. Observamos una puerta que se cierra y finalmente vemos el título del programa, en letras mayúsculas y amarillas. La puerta que se cierra nos permite completar cierto sentido de espacialidad que encontramos en la presentación, de modo que el vocablo “cámara" se presta a una segunda interpretación, ligada a su significado de pieza o sala. Esta segunda opción resulta en un punto más pertinente para buscar el anclaje del sintagma "Cámara del crimen", pues además nos remite a un Leitmotiv de la tradición del relato policial clásico: el misterio del cuarto cerrado. No sorprende, pues, encontrar el mismo sintagma que da título al programa televisivo en el

\footnotetext{
${ }^{6}$ Entendemos la transposición como “cambio de soporte o lenguaje de una obra o género” (Steimberg, 2013b: 115).
} 
nombre de un libro de ficción, cuando repasamos una lista de novelas clásicas enumeradas en una nota al pie de un ensayo de Jorge B. Rivera:

El problema del crimen cometido en un cuarto cerrado, al que no se puede acceder de manera verosímil y natural, es un problema que ha preocupado al hombre desde siempre. La literatura policial lo ha abordado prácticamente desde sus orígenes con Los crímenes de la calle Morgue (1841), de Edgar Allan Poe, y son significativamente numerosas las variables ensayadas para plantear y resolver el enigma y sus distintas variantes y subtipos: La cámara del crimen (1875), de Eugene Chavette, The Big Bow Mistery (1891), de Israel Zangwill, La forma equívoca (1911), de G. K. Chesterton, El lugar estrecho (1947), de Michael Gilbert, El misterio del alfiler, de Edgar Wallace, El visitante de medianoche, de S. S. Van Dine, El rey ha muerto, de Ellery Queen, El hombre hueco, John Dickson Carr, etcétera. (Rivera, 1996: 103).

La espacialización de la presentación y el antecedente de una novela policial con igual nombre - $L a$ cámara del crimen (1875), de Eugene Chavette- no clausuran la otra acepción del vocablo "cámara” -el aparato técnico que capta imágenes- ${ }^{7}$, pero en el segundo significado apuntado -la sala, la piezapodemos hallar una doble transposición desde la ficción policial: la réplica de un mismo sintagma y la demarcación de un espacio cerrado donde se comete un crimen (el espacio cerrado es, como ya mencionamos, un motivo muy reconocido del policial).

Aún podemos encontrar un tercer sentido vinculado al sintagma "Cámara del crimen": en la emisión del programa correspondiente al 26 de julio de 2014, cuando Canaletti refiere el caso del ingeniero Santos ocurrido en 1990, hace mención a la Cámara Nacional de Apelaciones en lo Criminal y Correccional de la Capital Federal, instancia judicial que coloquialmente es conocida como "Cámara del Crimen". Sin embargo, cuando esta institución es mencionada por su denominación abreviada, Canaletti se apresura a aclarar el nombre completo de dicha instancia judicial, de modo que en este caso "despega" su programa Cámara del crimen de la Cámara Nacional de Apelaciones en lo Criminal y Correccional de la Capital Federal: separa intencionalmente su trabajo periodístico de la responsabilidad propia de la esfera judicial (volveremos sobre esto en el próximo apartado, con una cita de una novela policial que trae a cuenta el propio Canaletti). Es decir: se construye como un enunciador externo al poder judicial y que busca $s u$ verdad desde el periodismo. De este modo, los continuos señalamientos en torno a los errores, fallas, descuidos y desmanejos del poder judicial propician una lectura que discrimina esta instancia institucional del programa televisivo-periodístico: la similitud de los significantes se contradice con una

\footnotetext{
${ }^{7} \mathrm{Al}$ contrario, podríamos decir que la presentación del programa mantiene la ambigüedad y se queda con ambas acepciones. Efectúa una suerte de "anclaje oscilante", pues, si bien muestra una cámara -habitación-, hay también otra cámara dispositivo- que ilumina ese lóbrego cuarto, que apunta y focaliza secuencialmente las distintas palabras mencionadas y que, en suma, hace visible la habitación. Por lo tanto, ambas cámaras no sólo mantienen la ambigüedad sino que incluso se coconstituyen.
} 
diferencia en los significados de cada uno de ellos. El programa televisivo, a través de su conductor, marca una postura definida y se aparta del poder judicial.

\subsection{Presentación del conductor y del co-conductor}

El conductor de Cámara del crimen, el periodista Ricardo Canaletti, construye su ethos de enunciador con un punto de partida claro ${ }^{8}$, en una secuencia que se repite en todas las emisiones: al entrar en escena, deja su saco en un perchero; y, antes de salir en el cierre del programa, lo toma y se lo lleva. Esta actitud simboliza a Canaletti como trabajador, pero en un sentido específico, que podemos rastrear en la subjetividad propia del detective de la tradición negra de la ficción policial: el detective profesional, que interviene mayormente como forma de sustentar su propia subsistencia. Es el caso de los famosos Philip Marlowe y Sam Spade, detectives de las ficciones de Raymond Chandler y Dashiell Hammett, respectivamente. Esta identificación con una subjetividad detectivesca profesionalizada, propia de la novela negra -en la que el detective recibe un pago por su trabajo-, se acentuará con un complemento: la escenificación del estudio del programa como suerte de despacho del detective, con reminiscencias de la oficina del detective de las producciones norteamericanas del film noir (esta presentación del espacio del programa no está desde el principio, sino desde el 13 de septiembre de 2014).

Otro rasgo éthico, es decir, relativo a la imagen que "Canaletti-enunciador" da de sí9, lo apreciamos en su vestimenta. Siempre usa un chaleco, que en la década de 1930 ó 1940 hubiera sido algo relativamente normal -o, al menos, común en las representaciones que encontramos en el cine negro norteamericano-, pero al usarlo en 2014 se convierte en una marca distintiva, en un atributo que inviste al enunciador con un atuendo propiamente detectivesco (podríamos decir, a lo Humprhey Bogart en el papel de Sam Spade, y en general según el estilo del private eye ${ }^{10}$. Pero Canaletti no sólo toma la vestimenta de los detectives privados de la serie negra; además habla muchas veces con destrezas verbales, juegos de palabras y usos coloquiales como los que usaban aquellos (por poner un ejemplo, podemos pensar en el comienzo de Cosecha roja de Dashiell Hammett). En la apertura de la emisión del 12 de abril, para introducir el caso del clan Puccio, encontramos un ejemplo que combina estas

\footnotetext{
${ }^{8}$ Según Maingueneau (2002), el ethos es una noción que permite reflexionar sobre el proceso general de adhesión de un sujeto a cierto posicionamiento y sobre la imagen que este enunciador da de sí.

${ }^{9}$ En este trabajo nos interesa la figura de Canaletti como enunciador que instituye, valga la redundancia, una enunciación, un "proceso subyacente por el cual lo expresado es atribuible a un yo que apela a un tü" (Filinich, 1998: 18). No analizamos ni nos interesa el comportamiento de Ricardo Canaletti como sujeto empírico. Al respecto, puede consultarse el texto de Filinich (1998), que exactamente establece la diferencia entre el sujeto de la enunciación -que remite, justamente, a la situación enunciativa- y el sujeto empírico -que se refiere al sujeto concreto de la situación comunicativa-.

${ }^{10}$ Debo la idea de la investidura a Marita Soto.
} 
cuestiones, cuando Canaletti dice: "Hoy vamos a hablar de un hijo de puta. Ah, perdón. Perdón, perdón. Perdón. En el periodismo, una de las cuestiones esenciales es ser preciso. Hoy vamos a hablar de un reverendo hijo de puta, de Arquímedes Puccio, el jefe de una familia de hijos de puta" (énfasis nuestro). En este fragmento citado tenemos un insulto reiterado y una sutileza léxica que se coloca por fuera de dicho movimiento iterativo: es el modificador directo, "reverendo", el vocablo que marca el juego con el lenguaje. Esto se combina, por supuesto, con la reflexión irónica sobre el rol del periodismo y las también irónicas- disculpas reiteradas, tras la "imprecisión" por no distinguir a un "reverendo hijo de puta" de un, digamos, mero hijo de puta.

La construcción de la figura de Canaletti también apela a razonamientos abductivos, a conjeturas efectuadas con certeza, para explicar elementos de los distintos casos referidos. En ese aspecto se aproxima a la figura de Sherlock Holmes, quien también efectuaba conjeturas para avanzar en la resolución de sus propios casos (Sebeok y Umiker-Sebeok, 1987). Según Sebeok y Umiker-Sebeok, "[l]a abducción es un instinto que se apoya en la percepción inconsciente de conexiones entre aspectos del mundo [...]. También aparece asociada o, mejor dicho, produce, según Peirce, un cierto tipo de emoción, que la diferencia tanto de la inducción como de la deducción" (1987: 35). Así, tendríamos que el carácter pasional, enfático y hasta exaltado que demuestra Canaletti resulta afín con las conjeturas abductivas, pues éstas llevan aparejadas un factor emotivo. En otros términos, podríamos decir que el carácter emotivo de la abducción permite una armonía entre el logos, el ethos y el pathos desplegado por el enunciador.

Si bien Canaletti se presenta fundamentalmente como periodista-investigador, con el correr de las emisiones vemos que también exhibe y explica un conjunto de conocimientos relativos a otros campos: quizá los más importantes sean los saberes legales -para leer e interpretar los expedientes judiciales- y los saberes médico-forenses -para leer los indicios que constituyen per se los cadáveres-. La lista de saberes remite, desde luego, al detective del policial clásico, con el ejemplo paradigmático de Sherlock Holmes, aunque, en el caso de Canaletti, los saberes son menos dispersos ${ }^{11}$.

Dado que en el párrafo precedente mencionamos que Canaletti "explica", debemos reconocer, aparte de su subjetividad detectivesca, otro aspecto que lo constituye como una suerte de "educador" para los televidentes ${ }^{12}$. Efectúa distinciones para instruir al público: por ejemplo, explica la diferencia

\footnotetext{
${ }^{11}$ En el segundo capítulo de Estudio en escarlata Watson anota los saberes y los límites de Holmes, y como resultado obtiene una lista de conocimientos sobre una dispersión de temas: geología, química, literatura sensacionalista, interpretación musical con violín, esgrima y derecho, entre otros (Conan Doyle, 2013).

${ }^{12} \mathrm{Al}$ respecto, debemos decir que la construcción de la figura del enunciador supone, a su vez, una construcción del público. En Cámara del crimen, los enunciatarios-televidentes se constituyen en un espectro de opciones que puede incluir -si pensamos en dos tipologías de un enunciatario próximo al género policial- los roles de aprendiz (de investigador) y de testigo.
} 
entre robo y hurto, entre robo y tentativa de robo, entre cadáver y cuerpo del delito, etcétera. De manera que, en este sentido, contemplamos en el ethos de Canaletti la emergencia de un yo pedagógico que toma distancia de la figura del detective en cualquiera de sus tipologías (tanto el armchair detective del policial clásico como el private eye del hard-boiled son sujetos a los que no les agrada mucho tener que dar explicaciones: por lo general, el primero lo hace de mala gana para esclarecer un crimen, en tanto que el segundo "se hace entender" a los golpes).

Otro aspecto relevante de la presentación del conductor lo hallamos en una construcción moral de sí mismo a lo Philip Marlowe, en el sentido -señalado por Saer (2004)- de erigirse como una suerte de héroe trágico que en su investigación sólo corrobora el carácter contaminado del mundo que lo rodea ${ }^{13}$. De este modo, más allá de la pretensión de esclarecer la verdad de un caso, Canaletti transmite otra verdad, propia del orden social en que vivimos: la policía y el poder judicial, que deberían velar por el cuidado de los ciudadanos, son instituciones ineficientes y corrompidas ${ }^{14}$.

Además de la conducción de Canaletti, el programa cuenta con un periodista de apoyo: Ignacio González Prieto. Si bien el primero es quien dirige y le dice al otro cuándo entrar en escena ("Vení, Nacho" es, emisión tras emisión, una de las frases que más repite Canaletti), ambos conforman una dupla que posee cierta reminiscencia con respecto a las parejas de detective y ayudante propios de la tradición clásica del policial. No por una cuestión de asimetría de saberes, sino más bien por respetar cierto principio mayéutico a través del cual sólo en el diálogo entre ambos se llega a la verdad. En la dupla Holmes-Watson, el primero aporta el conocimiento y los razonamientos y el segundo el asombro y el relato de los hechos, pero en esa asimetría existe una división de tareas según la cual uno piensa, el otro relata, y sólo así se arriba a una versión de la verdad -enunciada al lector a través de la voz de Watson-. En la dupla Canaletti-González Prieto podemos hallar un modus operandi similar, pues ambos poseen saberes necesarios y juntos participan en la reconstrucción de las historias. Aunque la división de tareas, para los dos periodistas, pasa por repartirse los distintos elementos del conjunto de la narración: Canaletti cuenta la historia cronológica de los sucesos criminales, en tanto que González Prieto suele ocuparse de detalles importantes, como la descripción del perfil -psicológico, esencialmente, pero

\footnotetext{
${ }^{13}$ Saer ve en Marlowe una "conciencia trágica”: “[m]ás que el investigador de un delito, Marlowe es un hombre que busca corroborar su situación trágica, y lo consigue por último” (2004: 250).

14 Grella (1980) sostiene que los policías representados en la ficción policial clásica son frecuentemente estúpidos e incompetentes, mientras que los del hard-boiled son brutales y corrompidos. En ese sentido, podríamos pensar que, en la perspectiva de Canaletti, la policía argentina real conjugaría los defectos de los policías representados en las dos grandes vertientes del género de ficción: estúpidos, incompetentes, brutales y corrompidos.
} 
también familiar y social- de los criminales y su prontuario, así como el análisis preciso de cuestiones legales y del devenir de las causas judiciales ${ }^{15}$.

Más allá de las diferencias, tanto en el relato policial clásico como en la crónica televisiva de Cámara del crimen hallamos una centralidad temática en torno al develamiento de la verdad o, más bien, en torno al conflicto y la tensión por ella. La disputa por la verdad es, a fin de cuentas, el gran foco de atención de la ficción policial, y lo mismo puede decirse de las crónicas policiales. De este modo, podríamos atisbar una hipótesis por la cual la transposición temática induce -o, al menos, permite- una transposición retórica (desde luego, no hay una relación necesaria en este punto, aunque no debemos perder de vista que el cambio de soporte torna inevitable un cambio en los procedimientos retóricos). Dados los parámetros clásicos del género policial, dos "periodistas-detectives" deberían tener más efectividad, en su interacción televisiva, para combinar esfuerzos y arribar al esclarecimiento de los casos.

Para cerrar este apartado, continuamos con una cuestión abierta en la sección precedente, en la que citamos la similitud de dos sintagmas y el esfuerzo por separar distintas esferas de la actividad humana: la periodística y la judicial. Pues bien, en la emisión del 26 de julio de 2014 hay una cita explícita, por parte de Canaletti, de una novela policial clásica, El misterio del cuarto amarillo de Gastón Leroux -obra también reconocida por ser un exponente del clásico misterio de cuarto cerrado referido en el apartado anterior-. Canaletti apela a la figura de Joseph Rouletabille, el protagonista de dicha novela: un periodista e investigador joven -o, más bien, adolescente-, que resuelve el caso referido en $E l$ misterio del cuarto amarillo. Hacia el final de la novela, cuando narra su versión de los hechos -que, en ese caso, coincide con la verdad de los hechos-, Rouletabille proclama: "No soy parte de la justicia, no soy parte de la policía; soy un humilde periodista y mi oficio no es hacer detener a la gente. Sirvo a la verdad como quiero... Es mi oficio... Preserven, ustedes, a la sociedad como puedan, ese es el suyo" (Leroux, 2002: 246; énfasis del original). Canaletti, en la emisión del 26 de julio, cita en parte leyendo y en parte de memoria este fragmento, de modo que un personaje de ficción le permite demarcar claramente su propio ethos de periodista-investigador de casos policiales. Así, vemos que, en primer lugar, encuentra una forma de identificarse con la auto-definición de un periodista de ficción, que no es sólo periodista, sino también investigador. En segundo lugar, se posiciona en conflicto con la justicia y la policía, que son los principales focos de crítica de Cámara del crimen (esta cuestión, de todas formas,

${ }^{15}$ En la emisión del $1^{\circ}$ de noviembre de 2014, González Prieto se ausenta. Canaletti refiere el caso de la cocineradescuartizadora Emilia Basil y, cuando concluye su relato, se da cuenta de que olvidó decir cuál fue la condena recibida finalmente por la mujer. Ante el repentino pero tardío recuerdo, lamenta con vehemencia: “¿Ven que hace falta que venga Nacho?". 
entra mayormente en el ámbito de lo temático). Y, en tercer lugar, establece el rol del periodistainvestigador como la búsqueda de la verdad.

Las cuestiones enumeradas en este apartado nos permiten ver que Canaletti solapa realidad y ficción en su propia construcción éhtica. El último aspecto indicado condensa este movimiento: apela a una figura de ficción para definir su rol periodístico.

\subsection{Ambientación escenográfica del programa}

Hasta ahora mencionamos dos cuestiones que hacen a la ambientación del programa: la secuencia de presentación y el perchero en que Canaletti deja su saco. Pues bien, en las primeras emisiones del programa, desde fines de marzo hasta mediados de mayo de 2014, el resto de la escenografía es "prestada": el escenario de Cámara del crimen es el mismo piso donde habitualmente vemos las emisiones de los noticieros regulares de $T N$.

Sin embargo, el panorama del escenario "prestado" se modifica desde el programa emitido el 17 de mayo de 2014, cuando la escenografía de fondo pasa a ser un una suerte de telón que se aproxima a un color amarillo-anaranjado a causa de la iluminación, junto a una serie de paneles "metálicos" dispuestos de manera vertical. Además de estos paneles, el fondo lo completan dos conjuntos de tres pantallas televisivas cada uno -ambos colocados por delante de los paneles "metálicos"-. Uno de ellos dispone las tres pantallas de forma vertical; el otro lo hace de manera horizontal. Estos dos conjuntos de pantallas televisivas conforman una suerte de división de la escenografía: por un lado, el conjunto vertical de pantallas forma parte de un primer sub-espacio que, además, contiene el perchero, donde Canaletti deja su saco al comenzar y lo retira al finalizar la emisión, y una pequeña mesa redonda de trabajo, donde apoya sus papeles, documentos y vasos con bebida. Por otro lado, el conjunto de los tres televisores dispuestos de manera horizontal se encuentra en un sub-espacio en el que hay una mesa más grande, rodeada de sillas, donde se desarrollan las entrevistas con los invitados -por lo general, víctimas, familiares, amigos, conocidos de víctimas, o allegados por distintos motivos a las circunstancias de los crímenes narrados-.

El segundo cambio se da a partir del 13 de septiembre de 2014, cuando el programa adopta una escenografía más "personalizada". El escenario donde "trabajan" ${ }^{16}$ se convierte en una verdadera oficina de detective privado: hay archiveros, carpetas con expedientes y un escritorio -además del perchero que, por supuesto, sigue presente-, todos con rasgos evidentemente anacrónicos. Si miramos The Maltese Falcon, en su versión de 1941 dirigida por John Huston, en el segundo minuto del film ya tenemos a Sam

\footnotetext{
16 Usamos las comillas con la intención de subrayar la representación del trabajo en tanto “periodistas-detectives”, y no en tanto vendedores de su fuerza de trabajo a un canal de televisión.
} 
Spade -representado por Humphrey Bogart- en su despacho, y en él podemos ver un claro ejemplo del mismo tipo de ambientación que nos presenta Cámara del crimen desde la fecha indicada. En dicha escena, vemos un archivero con carpetas, el escritorio del detective y hasta un perchero. Además, Sam Spade recibe a Ruth Wonderly/Brigid O’Shaunessy -Mary Astor- y la escucha en su oficina; esta secuencia se da de manera iterativa en Cámara del crimen, cuando Canaletti recibe en su sitio a víctimas y familiares de víctimas, a las que interroga pero también contiene.

En oposición a la primera escenografía, con el ambiente "prestado" del noticiero -el ventanal, la luminosidad y la vista hacia un afuera urbano-, desde la adopción de su última forma, el ambiente del programa pasa a ser más oscuro, por lo que nuevamente podemos trazar un paralelismo con el film The Maltese Falcon, en el que Spade hace cerrar y tapar las ventanas de su oficina. La intención de generar un ambiente más cerrado ya la percibimos, de hecho, en la primera transformación escenográfica de Cámara del crimen: el pasaje del ventanal del noticiero a un estudio que no ofrece la panorámica de ningún afuera y sólo se ilumina con luz artificial. A su vez, esta puesta en escena de un encierro puede remitirnos, otra vez, al motivo del cuarto cerrado propio de las ficciones policiales.

Ante los cambios vislumbrados, podemos apreciar un desplazamiento desde un espacio realista, el escenario "prestado" del noticiero habitual de $T N$-noticiero que, de hecho, tiene un pacto televisivo realista-, hacia un ámbito moldeado por la ficción -e independientemente de que también intente documentar casos reales-. La última escenografía, además, refuerza el sentido de "cámara” como habitación. Si bien en la presentación se mantiene la ambigüedad, la puesta en escena de la oficina del periodista-investigador refuerza el sentido de la espacialidad (lo mismo sucede con las puestas escenográficas de todas las "cámaras del crimen”, como veremos en el quinto apartado). Y refuerza la relevancia de una forma de componer y de narrar que apela a la ficción como método ineludible para hablar de casos reales.

Las transformaciones referidas, tanto la primera en mayo de 2014 como la segunda en septiembre del mismo año, marcan un itinerario hacia una identidad que va encontrando progresivamente el programa. A estas modificaciones podemos sumar la continuidad de elementos que están desde el primer programa en marzo y se consolidan durante todo el año: el ejemplo por antonomasia es, por supuesto, el perchero; sistemáticamente Canaletti abre el programa con la secuencia de colgar el saco, y cuando se despide lo toma nuevamente y se va. Esta marca, desde luego, también sufre un proceso de depuración, de "purificación" de la forma: con la nueva escenografía, se suman otros dos elementos, una puerta de entrada a la oficina y un interruptor de luz -luz general sobre el espacio escenográfico-, ambos incorporados en las secuencias de apertura y cierre del programa: Canaletti entra, enciende la luz y 
Hernán Maltz. El policial en los policiales...

cuelga su saco; y, al finalizar cada emisión, se despide con un saludo en italiano ${ }^{17}$, toma su saco, apaga la luz y sale. Estas acciones refuerzan el sentido de "trabajo" que leemos en el acto de enunciación del conductor y en la construcción de ese "sótano" -así se refiere a la nueva escenografía en la emisión de estreno de la misma, el 13 de septiembre de 2014- como su lugar de "trabajo".

\subsection{Presentación y representación de los casos referidos}

Independientemente de los cambios escenográficos, la estructura narrativa del programa se constituye por una puesta en escena fundante, dada por el momento inicial -Canaletti entra y deja su saco- y el momento final -Canaletti toma su saco y sale-. Entre esos dos puntos temporales, motivos instituyentes del contrato televisivo del programa, tenemos la presentación de los casos criminales.

La pauta básica de la narración de los casos es el propio Canaletti y su voz, su "vehemencia", su "compromiso" -insistimos: usamos las comillas para enfatizar un rasgo éthico que vemos en el enunciador-. Él cuenta las historias e Ignacio González Prieto las complementa con datos clave: en las primeras emisiones del año su rol se vincula mayormente con brindar indicios y mostrar elementos aparentemente triviales pero que en el contexto de la investigación son fundamentales para explicar el curso de los hechos ${ }^{18}$. González Prieto también brinda perfiles psicológicos, historias familiares, detalles de investigaciones policiales y pormenores de procesos judiciales -podríamos decir que, en el conjunto de las emisiones de 2014, esta última función es la preponderante-.

En el apartado sobre el modo de presentarse del conductor, mencionamos que el ethos de Canaletti lo posiciona como un enunciador que en muchas ocasiones acude a razonamientos abductivos. Sebeok y Umiker-Sebeok (1987) notan un factor común, a raíz de esta cuestión, en las figuras de Charles S. Peirce y Sherlock Holmes. Consignan:

Sherlock Holmes tiene tanto éxito en sus descubrimientos no porque no haga nunca conjeturas sino por lo bien que las hace. De hecho, sigue, inconscientemente, el consejo de Peirce para elegir la mejor hipótesis. «Tengo una vieja máxima -declara Holmes-, cuando se ha excluido lo imposible, lo que queda, aunque improbable, tiene que ser la verdad» [...]. Era la misma máxima

\footnotetext{
${ }^{17}$ Desde el fin de la emisión correspondiente al 13 de septiembre de 2014, Canaletti incorpora a su ceremonia de cierre un saludo en italiano: "Civediamo tra una settimana" ("Nos vemos en una semana"), que dice antes del saludo breve, también en italiano, ya incorporado previamente: "Arrivederci?".

${ }^{18}$ Por ejemplo, en la emisión del 29 de marzo de 2014, en el programa dedicado al caso del Motín de Sierra Chica en 1996, González Prieto trae a escena un jabón, un muñeco de peluche de un pájaro y una estampa de una virgen, como elementos aparentemente irrelevantes pero que ayudan a construir el perfil de los conjurados en dicho motín. Al respecto, debemos recordar las ideas de Ginzburg (2008) en torno al denominado paradigma indiciario, basado en ponderar los elementos que habitualmente se consideran poco importantes, en apariencia triviales, pero que finalmente dan la clave interpretativa de un problema.
} 
Hernán Maltz. El policial en los policiales...

de Peirce: «los hechos no pueden explicarse por una hipótesis más extraordinaria que ellos mismos; y, de varias hipótesis, debe adoptarse la menos extraordinaria». Parafraseando la discusión de Peirce podríamos decir que la mejor hipótesis es la más simple y natural, la más fácil y sencilla de probar, y, a pesar de esto, es la que contribuirá a la comprensión del más amplio grupo posible de hechos. (1987: 46-47).

Como ya mencionamos, la figura del enunciador construido en Cámara del crimen también responde a este tipo de máxima. Por ejemplo, en la emisión del 20 de septiembre de 2014 se trata el asesinato de María Marta García Belsunce ocurrido en 2002, y Canaletti descarta la primera explicación oficial de la muerte, basada en un "accidente" cuyas posibilidades reales de concreción hubieran sido imposibles, pues en dicho informe, según Canaletti, se describía una sucesión increíble de golpes "accidentales" y consecutivos: contra la barra de una ducha, contra un inodoro y contra un bidet.

Sobre el mencionado basamento narrativo, centrado en la voz y la narración del conductor, a lo largo de las emisiones vemos un itinerario en busca de una forma que se nutre de diversas y complementarias modalidades de exponer los casos criminales. Por ejemplo, el empleo de fragmentos de películas como modo de completar el sentido de las historias referidas es una práctica habitual que ya vemos desde la emisión del 5 de abril de 2014. Esta práctica se mantiene a causa de su efectividad y su carácter complementario: el cine permite mostrar espacios oscuros donde no alcanza con oír la voz de Canaletti y/o donde el registro auditivo resulta escaso para contar historias que claman por imágenes.

Desde la emisión del 17 de mayo de 2014 contamos con la presencia de un dibujante, Miguel Paradiso, que da lugar a una nueva sección: "El cuadro del crimen”. Esta nueva sección se incorpora como parte del trasfondo del programa, y sólo aparece en primer plano en dos momentos: al principio, cuando Canaletti lo presenta y, al final, cuando se acerca al dibujante para ver el resultado de su trabajo (Paradiso trabaja durante todo el programa, por lo que pasa a formar parte de la escenografía, hecho que se acentúa con la última ambientación del programa, en la que posee su propio escritorio incorporado al "sótano-oficina"). Canaletti siempre enfatiza que "el cuadro del crimen" es "un aspecto", "una parte" de lo que ve Miguel Paradiso en un caso policial. Esta aclaración resulta sugestiva para notar cierta "responsabilidad" del enunciador: si por un lado nos brinda su relato para acercarnos a "la verdad", por el otro suele efectuar reparos que recuerdan la mediación del dispositivo -el programa en su conjunto, que abarca una serie de sub-dispositivos- ${ }^{19}$.

Otro recurso clave del programa es la escenificación de espacios: no sólo tenemos la cronología de los hechos relevantes brindada por Canaletti, sino que se monta un espacio que representa un lugar significativo de un caso criminal: una habitación, un baño, un balcón, etcétera. Se trata de una

\footnotetext{
${ }^{19}$ En numerosas ocasiones, Canaletti interrumpe sus relatos para recordarnos que lo que hace en Cámara del crimen es una representación de los hechos.
} 
Hernán Maltz. El policial en los policiales...

herramienta que, como habíamos anticipado, se constituye como una suerte de marca, como un rasgo específico del programa, por lo que consideramos que amerita un desarrollo aparte.

\subsection{Usos de la escenificación en la narración de los casos criminales}

El espacio y, más precisamente, su representación, muchas veces ocupa un lugar clave en la ficción policial. Por ejemplo, en el ya citado y clásico libro de Gastón Leroux, El misterio del cuarto amarillo, tenemos mapas internos de la mansión de la familia Stangerson, o también podemos pensar en un ejemplo local con los relatos de Rodolfo Walsh incluidos en el libro Variaciones en rojo, donde se nos presentan esquemas de espacios para clarificar la composición del lugar de los hechos. Desde luego, tampoco hace falta contar con un mapa o un esquema para ver la importancia del espacio: podemos pensar en el relato "La muerte y la brújula", de Jorge Luis Borges, donde tenemos la presentación de una ciudad matematizada cual figura geométrica y en cuyos vértices se producen los crímenes.

En Cámara del crimen podemos hallar dos sentidos en la representación espacial. Por un lado, observamos una representación literal de espacios; se muestra el lugar del crimen: un living, una habitación, un baño, un balcón, etcétera -es decir, se representa una multiplicidad de variantes de la "Cámara del crimen"-. Así como la cronología pone en orden los hechos relevantes -o al menos produce un efecto de sentido que aparentemente lo hace-, el espacio también es un organizador que permite interpretar los hechos. Por citar un ejemplo que ya utilizamos, en la emisión del 20 de septiembre de 2014, cuando se trata el asesinato de María Marta García Belsunce ocurrido en 2002, Canaletti apela a la representación del baño donde fue encontrada, y usa dicho espacio, junto a un maniquí -que hace las veces de cadáver-, para mostrar las imposibilidades físicas relatadas en la primera versión oficial de la muerte de la socióloga, consistentes en una serie de golpes y lesiones imposibles de concretarse "por accidente", tal como indicaba aquella primera versión.

Por otro lado, hay una representación espacial de conceptos que hacen inteligible el caso -o, más precisamente, un uso del espacio que simboliza las dificultades para determinar la verdad de un caso-. En la emisión del 28 de junio de 2014 vemos sobre la pequeña mesa redonda una balanza desequilibrada por ciertos "obstáculos" que impiden que "se haga justicia". En la emisión del 19 de julio de 2014 tenemos un laberinto que representa las dificultades que imposibilitan esclarecer la muerte de Jimena Hernanández ocurrida en 1988. Canaletti narra la historia de la investigación y vincula sus vaivenes a posibles recorridos dentro de dicho laberinto. La conclusión, previsiblemente, es que el caso se trata de un "laberinto sin salida". En la emisión del 2 de agosto de 2014 contemplamos otro empleo de la escenificación en este mismo sentido: el relato de la muerte de Marianela Rago está repleto de elementos inciertos que impiden llegar a la verdad; para representar esta situación, en esta emisión vemos una gran fotografía de Marianela Rago, pero esta imagen resulta tapada casi en su totalidad por un muro de 
ladrillos. En la medida en que Canaletti cuenta los sucesos de la investigación, agrega un ladrillo a la pared por cada complicación que impide el esclarecimiento; y, de telón musical, escuchamos la canción Another Brick in the Wall de Pink Floyd. Con el ingreso en escena de González Prieto, éste refiere más obstáculos en el proceso investigativo, y por cada uno suma otro ladrillo, de modo que finalmente no podemos ver el rostro de Marianela Rago. En este caso, por lo tanto, la conclusión es que cada paso que se toma en la investigación resulta inútil e ineficiente, cada acción del proceso se describe como "otro ladrillo en la pared". Otro ejemplo significativo de este uso del espacio lo encontramos en la emisión del 9 de agosto de 2014, referida a la violación de un menor de edad cometida por Héctor Veira, el famoso caso Veira-Candelmo ocurrido en 1987. En el relato de esta historia, para mostrar la manipulación del caso por parte de los medios y la opinión pública en favor del victimario -Veira- y en detrimento de la víctima -Candelmo-, Canaletti se sirve de una serie de espejos que representan "la distorsión de los hechos". Así, con un efecto visual vemos remplazados los efectos distorsivos de las historias que circularon y aún circulan sobre este caso. Esto funciona como complemento a la voz del conductor, quien se sirve de los expedientes judiciales para mostrar la verdad de los hechos. Finalmente, abre una puerta que tiene un espejo que no deforma las imágenes, y allí encontramos una fotografía de cuerpo entero de Veira, a la que le cuelga un cartel que dice "VIOLADOR".

Un último empleo que deseamos destacar del recurso escenográfico lo hallamos en la emisión del 13 de septiembre de 2014, en la que se inaugura otra sección del programa: "Los casos de la máquina del tiempo". Canaletti nos hace ver una secuencia de la película The Time Machine, de 1960: vemos al protagonista entrar a un cuarto y observamos, justamente, la máquina del tiempo, donde se sienta -pues la máquina tiene una silla- y luego la enciende. Luego de mostrarnos esta escena fílmica, Canaletti copia la ficción: con el mismo telón musical de la película en cuestión, abre una puerta lateral del "sótanooficina" y, en una sala contigua, nos enseña una "máquina del tiempo" -un prototipo similar al del filmy explica que el modelo que apreciamos en la pantalla "se ha construido acá, en $T N$ ” (!). Canaletti se sube a la máquina y "viaja en el tiempo" para referirnos un caso criminal ocurrido en Olavarría, provincia de Buenos Aires, en 1888. Luego baja una manivela del artefacto y aclara que con ese movimiento apaga la máquina. Y explica: "La máquina viaja en el tiempo, no en el espacio. En una segunda etapa vamos a ver si la hacemos una 'máquina del tiempo voladora'. Por ahora es una máquina del tiempo. Viaja en el tiempo, no en el espacio” (!). Más allá del humor con que el conductor nos ofrece esta nueva sección, una vez más resulta sugestivo cómo Cámara del crimen apela a un recurso retórico que consiste en usar y hacer evidente un dispositivo ficticio, que en esta ocasión nos da acceso a historias criminales del pasado. 


\section{Conclusiones}

En el desarrollo de nuestro trabajo analizamos un conjunto de pasajes específicos, un conjunto de modos de hacer y componer transpuestos de la literatura y el cine policiales hacia un noticiero de casos criminales -aunque, como ya advertimos, esto no implica que se trate de las únicas formas de componer que se utilizan en Cámara del crimen-. Para tal fin, distinguimos cinco dimensiones en las que observamos dichas transposiciones y aprehensiones de retóricas del género policial: la presentación del programa; el modo de presentarse del conductor y del co-conductor; la ambientación espacial del propio programa; el modo de presentar y representar los casos referidos; y los usos de la escenificación en la narración de las historias.

A raíz de las descripciones y exposiciones analíticas desarrolladas, deseamos finalizar nuestro trabajo con dos conclusiones.

Por un lado, observamos que el empleo de los recursos retóricos señalados tiende a ocupar un rol preponderante en el programa: el escenario televisivo presentado como un "sótano-oficina", las puestas en escena literales y conceptuales para representar los casos criminales, la vestimenta y los rituales de entrada y salida de Canaletti, etcétera. Se trata de elementos que nos habilitan a pensar que, más que la verdad, importa cómo se la cuenta. En ese sentido, consideramos que en Cámara del crimen, en sus particulares modos de narrar, hay una tematización de lo retórico ${ }^{20}$. Es decir, lo retórico -el cómo- se impone por sobre lo temático -el qué-. Esto, a su vez, demuestra cierta inteligencia estratégica del programa, en un sentido comparable al que Verón sostiene en su análisis de la prensa gráfica: “el éxito (o el fracaso) no pasa por lo que se dice (el contenido), sino por las modalidades de decir el contenido" (2005: 174; énfasis del original).

Por otro lado, a partir de la multiplicidad de recursos compositivos que el programa expone, podemos atisbar una segunda conclusión, ligada a la hipótesis que habíamos anunciado en la introducción de nuestro escrito: señalábamos que, para contar casos reales, en Cámara del crimen hay una necesaria apoyatura en discursos ficcionales, literarios y fílmicos, especialmente del género policial (y, por esto mismo, sostuvimos en la introducción y reafirmamos en este cierre que resulta pertinente concebir el programa en conjunto con otras ficciones y programas televisivos que trabajan, con mayor o menor distancia, en relación al amplio género policial). Pues bien, si Osvaldo Di Paolo (2011) analiza ficciones policiales derivadas de casos criminales reales, nosotros agregaríamos que esos mismos casos reales ya vienen compuestos por un proceso de ficcionalización -o al menos eso observamos en nuestro análisis de Cámara del crimen-. De este modo, la "clave hermenéutica” (Grieco y Bavio, 2016), la

${ }^{20}$ Debo esta idea a Oscar Steimberg. 
Hernán Maltz. Elpolicial en los policiales...

“máquina de leer” (Narcejac, 1986) que es la ficción policial, al mismo tiempo resulta, según nuestra perspectiva, una clave performativa, una máquina de escribir. 
Hernán Maltz. El policial en los policiales...

\section{Bibliografía}

Bremond, Claude (1975). "Presentación”. Cohen, Jean; Todorov, Tzvetan; Simeray, Jean; Bremond, Claude; Grupo $\mu$; Durand, Jacques... Genette, Gérard, Investigaciones retóricas II . Buenos Aires: Tiempo Contemporáneo: 9-10.

Caldwell, John Thornton (1995). Televisuality: Style, Crisis, and Authority in American Television. New Brunswick: Rutgers University Press.

Conan Doyle, Arthur (2013). Estudio en escarlata. Buenos Aires: Cántaro.

Di Paolo, Osvaldo (2011). Cadáveres en el armario. El policial palimpséstico en la literatura argentina contemporánea. Buenos Aires: Teseo, Austin Peay State University.

Fiske, John, y John Hartley (2003). Reading Television. Londres, Nueva York: Routledge.

Filinich, María Isabel (1998). Enunciación. Buenos Aires: Eudeba.

Ginzburg, Carlo (2008). "Indicios. Raíces de un paradigma de inferencias indiciales". Mitos, emblemas, indicios. Morfología e historia. Buenos Aires: Prometeo Libros: 171-221.

Grella, George (1980). “The Hard-Boiled Detective Novel”. Winks, Robin W. (ed.), Detective Fiction. A Collection of Critical Essays. New Jersey: Prentice-Hall, Englewood Cliffs: 104-120.

Grieco y Bavio, Alfredo (2016). “De Okupas a Tumberos: la verdad nos hará libres”. Setton, Román (comp.), Ficciones policiales argentinas (1870-2015). La literatura en la literatura, la historieta, el cine y la televisión. Buenos Aires: Blatt \& Ríos. [En prensa]

Grimson, Alejandro (2015). “La crisis de la interpretación”. Anfibia.

Leroux, Gastón (2002), El misterio del cuarto amarillo. Leroux, Gastón; Borges, Jorge Luis, El misterio del cuarto amarillo - Emma Zunz . Buenos Aires: Cántaro: 27-279.

Link, Daniel (2003). “El juego silencioso de los cautos”. Link, Daniel (comp.), El juego de los cautos. Literatura policial: de Edgar A. Poe a P. D. James. Buenos Aires: la marca: 9-17.

Maingueneau, Dominique. "Problèmes d’ethos". Pratiques, 113/114 (2002): 55-67.

Narcejac, Thomas (1986). Una máquina de leer: la novela policial. México D. F.: Fondo de Cultura Económica.

Rivera, Jorge B. (1996). “Introducción al relato policial en la Argentina”. Lafforgue, Jorge; Rivera, Jorge B., Asesinos de papel. Ensayos sobre narrativa policial. Buenos Aires: Colihue: 83-104.

Saer, Juan José (2004). “El largo adiós”. El concepto de ficción. Buenos Aires: Seix Barral: 244-251. 
Sebeok, Thomas; Umiker-Sebeok, Jean (1987). Sherlock Holmes y Charles S. Peirce. El método de la investigación. Barcelona: Paidós.

Steimberg, Oscar (2013a). "Proposiciones sobre el género". Semióticas. Las semióticas de los géneros, de los estilos, de la transposición. Buenos Aires: Eterna Cadencia: 45-96.

Steimberg, Oscar (2013b). "El pasaje a los medios de los géneros populares”. Semióticas. Las semióticas de los géneros, de los estilos, de la transposición. Buenos Aires: Eterna Cadencia: 115-156.

Verón, Eliseo (2005). “Cuando leer es hacer: la enunciación en el discurso de la prensa gráfica”. Fragmentos de un tejido. Barcelona: Gedisa: 171-191. 